\title{
Nutritional Status among under-5 Children of a selected slum in Dhaka city
}

\author{
M A Hoque ', M A Sayeed ${ }^{2}$, M R Ahsan ${ }^{3}$, M A A Mamun ${ }^{4}$, F Salim ${ }^{5}$
}

Abstract

Background : Malnutrition is a serious public health problem that has been linked to increase risk of morbidity and mortality. Child malnutrition causes $27 \%$ of child deaths in developing countries in 2015.

Objective : To estimate the nutritional status of under five children of a selected slum in Dhaka city.

Methodology : This was a descriptive cross sectional study and conducted among 100 under 5 children purposively selected at Agargaon slum in Dhaka city during January-2015 to July-2015. Anthropometric measurements were taken by using standard methods. Those were weight, height, MUAC. Information regarding age of children was taken from patient's birth certificates or hospital records. Nutritional status was estimated by calculating Z-score, weight for age, height for age, weight for height and mid upper arm circumference. Data were analyzed using SPSS version 16.

Results : Mean age of the study population was 32.95 months. Male was 52\% and female was $48 \%$. Regarding Anthropometric assessment according to weight for height Z-score, $39 \%$ were wasted moderately and $13 \%$ were severely wasted and height for age Z-score, showed $47 \%$ of children were stunted moderately and $14 \%$ children were severely stunted. According to weight for age Zscore, $46 \%$ of children were moderately underweight and $16 \%$ children were severely underweight. According to MUAC classification $43 \%$ of children were in border line and $16 \%$ were malnutrition.

Conclusions : Overall, nutritional status of the under 5 child of slum of Agargaon were not satisfactory.

Keywords : Under 5 children, Slum, Nutritional status, Anthropometry, Z-score, MUAC.

Northern International Medical College Journal Vol. 7 No. 02 January 2016, Page 143-145

${ }^{1}$ Dr. Md. Aynal Hoque Assistant Professor Dhaka Shishu Hospital, Dhaka

${ }^{2}$ Dr. Md. Abu Sayeed Intensivist (cardiology) Dhaka Shishu Hospital, Dhaka

3 Dr. Mohammed Rizwanul Ahsan Registrar

Dhaka Shishu Hospital, Dhaka

${ }^{4}$ Dr. Mohammad Abdullah AI Mamun Assistant Professor Dhaka Shishu Hospital, Dhaka.

${ }^{5}$ Dr. Farhana Salim

Assistant Professor

Dept. of Community Medicine

Shahid Monsur Ali Medical

College, Dhaka.

Correspondence

Dr. Md. Aynal Hoque

Assistant Professor

Dhaka Shishu Hospital, Dhaka

\section{Introduction}

Malnutrition is the most common nutritional disorder in developing countries and it remains one of the most common causes of morbidity and mortality among children worldwide. ${ }^{1}$ Nearly half of all deaths in children under 5 are attributable to under nutrition. Under nutrition puts children at greater risk of dying from common infections, increases the frequency and severity of such infections and contributes to delayed recovery. In addition, the interaction between under nutrition and infection can create a potentially lethal cycle of worsening illness and deteriorating nutritional status. Poor nutrition in the first 1,000 days of a child's life can also lead to stunted growth, which is irreversible and associated with impaired cognitive ability and reduced school and work performance. ${ }^{2}$ Good nutrition is the cornerstone for survival, health and development. Malnutrition is the underlying contributing factor in about $45 \%$ of all child deaths, making children more vulnerable to severe diseases. 5.9 million Children under the age of 5 died in 2015. Child malnutrition causes $27.9 \%$ of child deaths in developing countries in 2015. ${ }^{3}$

The three main indicators used to define under nutrition, are underweight, stunting and wasting, represent different histories of nutritional status to the child. That occurring primarily in the first 2-3 years of life in children. Linear growth retardation (stunting) is frequently associated with repeated exposure to adverse economic conditions, poor sanitation, and the interactive effects of poor energy and nutrient intakes and infection. Low weight-for-age indicates a history of poor health or nutritional insult to the child, including recurrent illness and/or starvation, while a low weight-for-height is an indicator of wasting (i.e., thinness) and is generally associated with recent illness and failure to gain weight or a loss of weight. ${ }^{4} \mathrm{~A}$ good percentage of the population of Dhaka city is living in the slums. ${ }^{1}$ In slum areas of Dhaka city there is a very high prevalence of malnutrition. The prevalence of stunting, wasting and underweight are $68.4 \%$, $31.2 \%$ and $73.2 \%$, respectively. The prevalence 
of malnutrition is higher in Dhaka slums than the national average which is $49 \%$ for stunting, $17.5 \%$ for wasting and $56 \%$ for underweight, and indicates exceptionally high levels of malnutrition as judged against World Health Organization criteria. $^{3}$ Malnutrition is increasing rapidly among socioeconomically deprived sectors of the developing countries where poverty, unemployment, literacy and ignorance are rampant. ${ }^{2}$

\section{Methodology}

This was a descriptive cross sectional study carried out during January-2015 to July-2015 at Agargaon slum of Dhaka city. A total 100 under- 5 children were selected purposively according to inclusion criteria: i) those babies living in slum at least 6 months, ii)willing to participate and iii) 2 months to 5 years ages of children Exclusion criteria were - Seriously ill, mentally retarded and unwilling to participate in the study were excluded from the study.

Following parameters were studied: (1) Height: 2 months to 2 years of age by infantometer in lying position and after 2 years up to 5 years in standing position by stadiometer.

Height was recorded in standing position without foot wear; foot placed closed together, knees straight and heels, buttocks and shoulder in contact with the vertical wall. The child was held firmly with eyes looking straight up and the body held as straight as possible with the knees pressed straight. The height was measured to the nearest millimeter.

Weight: Weight was taken by electronic weighing machine. The child was asked to stand on the weighing machine with minimum clothing and without shoes and any weight in hands or touching or catching other things. Weight was recorded to the nearest grams.

Age: Asking parents or from birth certificate/ hospital records.

Mid Upper Arm Circumference (MUAC): MUAC is an easy and useful measurement. It was recorded by measuring tape. The middle of the left arm will be detected by the midpoint of a line between the tip of the acromion process of scapula and olecranon process of ulna. Then at the midpoint the measuring tape will be wrapped round gently but firmly avoiding compression of soft tissue keeping the arm in hanging and extended position at the side of the body, then the reading will be taken to the nearest $0.1 \mathrm{~cm}$.

WHO classification was used for the assessment of malnutrition. Based on the age, body weight and height, a number of indices such as height-for-age, weight-for-age and weight-for-height have been suggested. The children were classified using three categories: 'underweight' (low weight-for-age), 'stunting' (low height-for-age) or 'wasting' (low weight-for-height). Charts of Anthpopmetric values are used for this study.

Underweight was defined as low weight-for-age and it reflects past (chronic) and present (acute) under nutrition. Children with $z$-scores $<-2.00$ are said to be underweight. Stunting is defined as a low height-for-age for children, and it measures the past (chronic) child under nutrition. Children with z-scores $<-2.00$ are said to be stunted. Wasting is defined as low weight-for-height for children, and it is a measure of current or acute under nutrition. Children with z-scores $<-2.00$ are said to be wasted. ${ }^{3}$ Informed consent was taken from informant mother or care giver before taking data.

A questionnaire was prepared for data collection. All the collected data entered into the computer and analyzed with the help of SPSS (Statistical package for social science) windows programs version 16.

\section{Results}

It was found that, the age of the children ranging between 0.1 and 60 months. The mean age of the children were 32.95 months with standard deviation \pm 9.91 months. Among them $19 \%$ of the children were in 01-12 month age group, 20\% were in 13-24 month age group, 27 were in $25-36$ months age group, $19 \%$ were in 37-48 months age group and $15 \%$ in $49-60$ months age group. It was evident from the study that $52.0 \%$ study children were male and $48 \%$ were female (Table-I)

$\begin{array}{ccc}\begin{array}{c}\text { Table-I : } \\ \text { Age in months }\end{array} & \begin{array}{c}\text { Frequency } \\ \text { 01-12 }\end{array} & \begin{array}{c}\text { Percentage } \\ 13-24\end{array} \\ 25-36 & 20 & 19.0 \\ 37-48 & 27 & 20.0 \\ 49-60 & 19 & 27.0 \\ \text { Total } & 15 & 19.0 \\ & 100 & 15.0 \\ \end{array}$

Mean $\pm \mathrm{SD}=32.95 \pm 9.91$ months.

$\begin{array}{ccc}\text { Sex } & \text { Frequency } & \text { Percentage } \\ \text { Male } & 52 & 52.0 \\ \text { Female } & 48 & 48.0 \\ \text { Total } & 100 & 100.0\end{array}$

According to MUAC classification, $43.0 \%$ of study children borderline malnutrition and $16.0 \%$ were malnourished (Table-II)

Table: - II: Nutritional status of the children by MUAC classification

$\begin{array}{ccc}\text { MUAC classification } & \text { Frequency } & \text { Percentage } \\ \text { Malnourished } & 16 & 16.0 \\ \text { Borderline } & 43 & 43.0 \\ \text { Normal } & 41 & 41.0 \\ \text { Total } & 100 & 100.0\end{array}$

According to Weight for Height Z-score, it was found that 39\% of children wasted and $13 \%$ severe wasted. (Table-III)

Table- III : Nutritional status of the children by Weight for Height Z-score

$\begin{array}{ccc}\text { Weight for Height Z- score } & \text { Frequency } & \text { Percentage } \\ \text { Not Wasted } & 48 & 48.0 \\ \text { Moderate Wasted } & 39 & 39 \\ \text { Severe Wasted } & 13 & 13.0 \\ \text { Total } & 100 & 100.0\end{array}$


According to Height for Age Z-score, it was found that $47 \%$ of children moderately stunted and $14.0 \%$ children severely stunted (Table-IV)

$\begin{array}{ccc}\begin{array}{c}\text { Table -IV : Nutritional status of the children by Height for Age } \\ \text { Z-score }\end{array} & & \\ \text { Height for Age Z- score } & \text { Frequency } & \text { Percentage } \\ \text { Severe Stunted } & 14 & 14.0 \\ \text { Moderate Stunted } & 47 & 47.0 \\ \text { Not Stunted } & 39 & 39.0 \\ \text { Total } & 100 & 100.0\end{array}$

According to weight for Age Z-score, it was found that $46 \%$ of children moderately underweight and $16.0 \%$ children severely underweight (Table-V)

\begin{tabular}{|c|c|c|}
\hline Weight for Age Z- score & Frequency & Percentage \\
\hline Severe Underweight & 16 & 16.0 \\
\hline Moderate Underweight & 46 & 46.0 \\
\hline Not Underweight & 38 & 38.0 \\
\hline Total & 100 & 100.0 \\
\hline
\end{tabular}

\section{Discussion}

This descriptive cross sectional study was conducted with a view to determine the nutritional status of under five children from Agargaon slum. A total 100 children were studied. The age of the children was ranging between 01 and 60 months. The mean age of the children was 32.95 months with standard deviation \pm 9.91 . This result was consistent with the study done in India by Swaroop Kumar Sahu et al. ${ }^{5}$

In the study of Halder B (2000)6 male and female were 59\% and $41 \%$. According to statistical pocket Book of Bangladesh2004, the male and female were $51.2 \%$ and $48.0 \%$, which was almost similar to our present study where male and female were 52 and 48. Study conducted by Yasmeen S in Bangladesh male and female were found as $44 \%$ and $56 \% 7$.

Dasgupta et al. (2015) assessed anthropometric indices on 100 under-5 children with standard anthropometric indices such as weight for age, weight for height, height for age, and mid upper arm circumference prevalence of malnutrition were $42 \%$ (underweight), 30\% (wasting), 28\% (stunting), and 48\% (under nutrition), respectively. ${ }^{8}$ Sultan-Uz-Zaman et al. (2015) conducted a study on malnutrition on children of 18 months. The prevalence of underweight, stunting and wasting was $24 \%$, $36 \%$ and $8 \%$ respectively. ${ }^{9}$ Popat et al. (2014) conducted a cross sectional study and found prevalence of underweight, stunting and wasting was $32.4 \%, 46.1 \%$ and $17.2 \%$ respectively. ${ }^{10}$ In our study MUAC classification $43 \%$ of children were borderline and $16 \%$ were malnourished. This is similar to study in India by Dasgupta et al. ${ }^{8}$
Regarding Z-scores, it was found in the present study that, 39\% children were moderate wasted $13 \%$ severely wasted $47 \%$ moderate stunted and $14 \%$ severely stunted, $46 \%$ moderately under weight and $16 \%$ severely under weight. Child Nutrition SURVEY-2000 (ages 6-71 months) ${ }^{11,12}$ found in their survey that $51 \%$ of the children were moderately underweight and $13 \%$ severely underweight, 49\% moderately stunted and 19\% severely stunted and $12 \%$ moderately wasted and $1 \%$ severely wasted. According to Demographic and Health Survey- 19902000 (ages 0-59 months) ${ }^{11}$ it was found that $48 \%$ of the children were moderately underweight and $13 \%$ severely underweight, $45 \%$ moderately stunted and $18 \%$ severely and $10 \%$ moderately wasted and $1 \%$ severely wasted. These findings are similar with the current study findings.

\section{Conclusion}

In this study wasted, stunted and under nutrition were $13 \%$, $14 \%$ and $16 \%$ respectively (severe form) and mild/moderate wasted, stunted and underweight were $39 \%, 47 \%$ and $46 \%$ respectively. This study with small sample size cannot represent the national nutritional status of under five children. A large scale study is required to obtain the real situation.

\section{References}

1. Taha H. Musaa, Hassan H. Musab, Elrasheed A. Alia, Nazik E. Musa, Prevalence of malnutrition among children under five years old in Khartoum State, Sudan, Polish Annals of Medicine; June 2014. 21 (1): 1-7

2. UNICEF;, World Children Health Status http://data.unicef.org/nutrition/malnutrition.html\#sthash.pypLcs1R.dpuf

3. WHO Fact Sheet: http://www.who.int/mediacentre/factsheets/fs178/en/ accessed on 02.01.2015

4. Jai Prakash Singh, Shyam Bihari Gupta, Ved Prakash Shrotriya, Prabhu Nath.Singh. Study of Nutritional Status Among Under Five Children Attending Out Patient Department at A Primary Care Rural Hospital. Bareilly (UP) Scholars Journal of Applied Medical Sciences (SJAMS) 2013; 1(6):769-773.

5. Swaroop Kumar Sahu, S Ganesh Kumar, B Vishnu Bhat, K C Premarajan, Sonali Sarkar, Gautam Roy, and Nitin Joseph. Malnutrition among under-five children in India and strategies for control. J Nat Sci Biol Med. 2015 Jan-Jun; 6(1): 18-23. doi: 10.4103/0976-9668.149072 PMCID: PMC4367032

6. Halder B. A study on Nutritional Status of Under 5 Children of Class III\&IV Employees of Army in Dhaka cantonment, Dhaka IPGM \&R; 2000:38-55.

7. Yasmeen S. Nutritional status of under 5 children attending the out patient department of paediatrics in Bangladesh Medical College, Dhaka. 1996; 38-41.

8. Dasgupta A, Sahoo SK, Taraphadar P, Preeti PS, Biswas D, Kumar A, Sarkar I: Composite index of anthropometric failure and its important correlates: a study among under- 5 children in a slum of West Bengal, India. International Journal of Medical Science and Public Health. 2015; 4: 414-419.

9. Sultan-Uz-Zaman, Seoty NR, Alam M, Haque R, Yasmin N. Household food insufficiency and child nutritional status in urban slum. Dhaka, Bangladesh Acta Medica International. 2015; 2:65-69

10. Popat CN, Chaudhari AI, Mazumdar VS, Patel SV. A cross sectional study to measure the prevalence of malnutrition and factors associated with malnutrition among under five children of an urban slum of Vadodara city. Journal of Research in Medical and Dental Science. 2014: 2: 59-64

11. Bangladesh Demographic and Health Survey 2000, NIPORT, Bangladesh

12. Nutritional Situation and Nutrition Programs in Bangladesh. Prepared Jointly by NNP,BNNC,IPHN for Global Nutrition Seminar 2005, March 2005; 1.2. 